\title{
Erklärung der Zeichen und Abkürzungen
}

*) Anmerkung đes Herausgebers.

1) Anmerkung innerhalb der abgedruckten Urkunde.

[ ] Innerhalb der Kirchenordnung von I924 (S. I-436) steht in eckigen Klammern der deutsche Text, soweit er nicht aus der amtlichen deutschen Ausgabe der Kirchenordnung einschließlich der Liturgie entnommen, sondern für das Corpus Confessionum neu hergestellt ist (vgl. die Anmerkungen des Herausgebers S. I und S. 367). Eckige Klammern im englischen Text entsprechen dem Originaldruck. In den Anderungen der Kirchenordnung von 1928 (S. 436-6ro) sind die neuen deutschen Übersetzungen nicht in eckige Klammern gesetzt. Hier stehen in eckigen Klammern sowohl beim englischen wie beim deutschen Text die Verweisungen auf die $\S \S$ der Ausgabe von 1924 (vgl. die Anmerkungen des Herausgebers S. $436 \mathrm{f}$. und S. $604 \mathrm{ff}$.).

() Wenn innerhalb der Katechismen (S. 610-719) die Angaben von Bibelstellen in runden Klammern stehen, so bedeutet dies, daß an dieser Stelle bei der Herstellung des Textes für das Corpus Confessionum kein ausgeführter Wortlaut eines Spruches gestrichen worden ist (vgl, die Anmerkungen des Herausgebers S. 610, 643, 655, 667, 670, 685, 689). Wo das Letztere der Fall gewesen ist, sind die Angaben der Bibelstellen nicht eingeklammert.

Über die Bezifferung der Änderung der Kirchenordnung (S. 436-610) gibt die Obersicht der Paragraphierung (S. 436-439) Aufschluß.

Ld., N. Y., Bm., Zr. sind in der Bibliographie (S. XXX-XXXVII) die Abkürżungen für die Hauptverlagsorte: London, New York, Bremen, Zürich.

S. $=$ Seite, Z. = Zeile. 